\title{
AEC' Exchange Rates Risk on Interbank Money Market: Evidence from Thailand
}

\author{
Gongkhonkwa Rujira ${ }^{1} \&$ Wang Zongjun ${ }^{1}$ \\ ${ }^{1}$ School of Management, Huazhong University of Science and Technology, Wuhan, Hubei, China \\ Correspondence: Gongkhonkwa Rujira, Building 7 Room104, Huahong Foreign Student Apartment, C3 District, \\ Huazhong University of Science and Technology, Hongshan Area, Wuhan City, Hubei Province, 430074, China. \\ Tel: 86-159-2623-0865. E-mail: galileoh@hotmail.com
}

Received: April 23, 2013

Accepted: May 13, $2013 \quad$ Online Published: May 21, 2013

doi:10.5539/ijef.v5n6p20

URL: http://dx.doi.org/10.5539/ijef.v5n6p20

\begin{abstract}
Exchange rate risk is one part of systematic risk that able to be transfer between countries and markets. Therefore, many researchers are seeking the suitable way to reduce the exchange rate risk. This study aims to analyze the AEC's exchange rates risk on interbank money market thereby we perform our test with econometric test by using the linear regression to be our model. This study has found some evidence from the variance decomposition test and impulse response test that suggested the exchange rates of AEC member countries such the Indonesian Rupiah (IDR), and Philippine Peso (PHP) can be explained the interrelationship between exchange rate and BIBOR better than other currencies. Moreover, we also found the degree of relation of the exchange rates vary direction with the tenor of BIBOR as well. And, almost every currency of the AEC's exchange rates had positive relation on BIBOR except the PHP. The results from this study will be extending knowledge and understanding of exchange rate risk on BIBOR to the central bank, financial institution, and everyone who interesting in exchange rate risk moreover this result can apply for risk management as well.
\end{abstract}

Keywords: exchange rate risk, Asean Economic Community, interbank money market, Bangkok Interbank Offered Rate

\section{Introduction}

The global financial turmoil has both of short-term and long-term effect to the financial stability. However, that problem is not only happen on Thailand but it also happened around the world. Owing to recession, an unemployment rate and inflation in each country will increase, in part of financial institutions will concern with the counterparty risk, interest rate risk and liquidity risk between banks, and the stock market will drop dramatically afterward the investor confidence index will fall too therefore they have change their investment behavior.

In recent years the financial institutions are taking into account the risk between countries and markets which able to be an effect to the financial and real-sector channels. Therefore many researchers in many sectors of economy, such as who work in financial institutions, stock market, government's organization or the other sector who were influence by the financial turmoil have investigate what kind of risk or variable has directly and indirectly significant effect on their organization and to enlarge knowledge and know-how about risk management.

The financial market is a one important part of Thailand's economy for move on the economic sector into global market. The Interbank money market is the market which refers to the borrowing and lending money between financial institutions with the interbank interest rate. The Interbank interest rates of Thailand are regulated and taken by the Bank of Thailand's Monetary Policy Committee that we called "Bangkok Interbank Offered Rate". The Bangkok Interbank Offered Rate (BIBOR) is quoted by 17 contributors in Bangkok interbank market and a reference rate is published by the Bank of Thailand (BOT) at 11.15 a.m. (Bangkok time) in every working day. The BOT try to promote the BIBOR to be a reference rate for financial transactions that effective from year 2005.

The Asean Economic Community (AEC) is the organization between countries will be the establishment of an AEC by 2015, to concern about the economic integration of ASEAN member countries which consist of Brunei 
Darussalam, Cambodia, Indonesia, Lao PDR, Malaysia, Myanmar, Philippines, Singapore, Thailand, and Vietnam. The AEC's aim mainly to be a single market and production base, highly competitive economic region, a region of equitable economic development, and a region fully integrated into the global economy. Additionally, the AEC will transform ASEAN into a region with free movement of goods, services, investment, skilled labor, and frees flow of capital.

Regarding the systematic risk such an exchange rate risk, in this study we attempt to improve the knowledge and understanding on an impact of AEC's exchange rates risk on Thailand's interbank rate and specify which currency of AEC has more significant effect to the BIBOR.

The rest of this paper is organized as follows. The first part is the description of data and literature review. The second part is the experimental methodology and hypothesis. The third part is the empirical results. The last part is the conclusion and suggestion.

\section{Description of Data and Literature Review}

\subsection{Definition of Risk and Risk Management}

As mentioned in the introduction, in this paper we propose a general framework to measure the exchange rate risk of AEC member countries on BIBOR. Risk is refers to an uncertainty about benefits or costs and arises whenever there is imperfect information about something that will be affected a benefits or costs in the future (Ivan and Dale, 2007).

A method of risk management the manager should identify and evaluate the most promising areas where risk might be reduced. Hans and Oh (2007) mentioned that "two objectives of risk management are provide the best prospects for taking actions to reduce risk and discovering a new opportunity". There are six steps to integrate in risk management framework (National Institution of Standard and Technology, 2008) includes:

1) Define criticality or sensitivity of information system according to potential worst-case, adverse impact to mission or business.

2) Select baseline security controls; apply tailoring guidance and supplement controls as needed based on risk assessment.

3) Implement security controls within enterprise architecture using sound systems engineering practices; apply security configuration settings.

4) Determine security control effectiveness.

5) Determine risk to organizational operations and assets, individuals, and other organizations.

6) Continuously tract changes to the information system that may affect security controls and reassess control effectiveness.

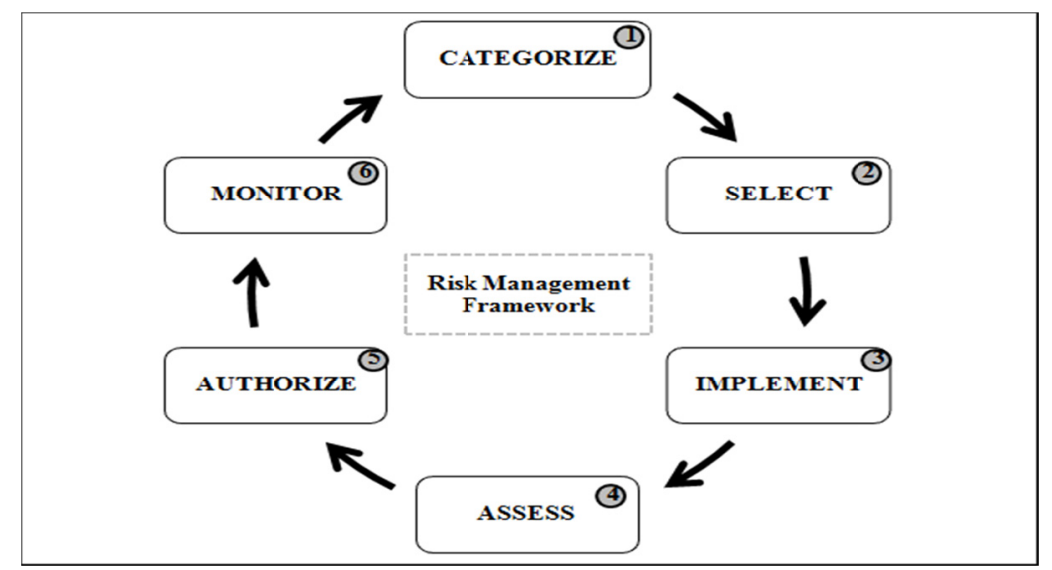

Figure 1. Risk management framework (adopt from National Institute of Standards and Technology, 2008)

Notes:(1)=Risk Categorize; (2) =Risk Select; (3) = Risk Implement; () = Risk Assess; () = Risk Authorize; ()= Risk monitor

In addition, the risk is composed of two types (Stephen et al, 2005).

1) Systematic risk is refers to any risk that affect a large number of assets, each to a greater or lesser degree. 
2) Unsystematic risk is refers to a risk that specifically affect a single asset or a small group of asset and sometimes we called "idiosyncratic risk".

As described above, an exchange rate is some part of systematic risk which an effect of exchange rate risks on one currency able to be transfer to the other currency both in the same market and different market. However, we cannot avoid the impact of the systematic risk but we can reduce an effect of it.

In Thailand, the BOT aims to create a mechanism to protect against the risk of economic turmoil, how to make a decision in response to the institutional and macroeconomic changes surrounding monetary policy for each period (Kiyotaka, 2006) and to set up BOT's decision making process to ensure a good governance, promote the stability, and soundness of financial market and economic system. Furthermore, the Monetary Policy Committee (MPC) is the one of the main committees of the BOT who responsible for setting the monetary, to monitor an internal and external economic condition, and makes assessments and policy decisions based upon the data which provided by the BOT.

\subsection{Definition of Interbank Money Market and Interbank Rate}

The interbank money market is a subsection of the money market which refers to borrowing and lending money between banks and most interbank transactions are maturity for periods not over one year. The banks borrow money from surplus banks in order to manage liquidity and satisfy regulations have to pay an interbank rate which means a rate of interest charged on loan between banks. Moreover, the interest rates charged are depending on many variables, such as term of the contract, a prevailing rate, the availability of money in the market.

The Interbank money market is a significant part of Thailand's financial market and Thailand's economy. Jens (2006) noted that "the central bank usually using the average overnight interbank rate for expected the liquidity situation" and Dieter and Jan (2011) also noted the "the Interbank rate able to be using for an indicator for expected the monetary policy. The Interbank rate of Thailand's money market is called "BIBOR" which quotes by the Bank of Thailand (BOT) at 11.15 a.m. (Bangkok time) of each working day.

From previous literature review which related to interbank money market and interbank rate includes, Anoop et al. (2007) noted that "the monetary policy influence the market interest rate" which relative to Ming et al. (2008) who suggested that "the monetary policy rate had more influence and faster adjustment speed on short-term interest rate more than long-term interest rate".

According to borrowing or lending money between banks the surplus banks should be concerning the default risk of counterparty that about an ability and willingness to pay a principal and interest on maturity date (Robert, 2011). In case if borrower cannot pay for principal and interest or insolvency for a variety reason as a result it able to lead to domino effects both direct and indirect to the counterparty (Christian and Andreas, 2004).

However, Asghar and Kevin (2010) suggested that "inflation can be explained a default risk". And the standard measurement tools to gauge the default risk is credit ratings that provided by Nationally Recognized Statistical Rating Organization (NRSROs), for instance, the Standard \& Poor's (S\&P), Moody's and Fitch Ratings. Deborah, Gary and Simon (2011) suggested that "in practice, the methodology to guarantee the default risk on future the surplus banks ought to charge higher rate of interest or require a higher compensation for default risk on loan".

\subsection{Definition of Exchange Rate and Exchange Rate Risk}

The liberalization of financial markets has caused exposure to sources of risk thereby the investors must know the factor both cross-sectional and cross country variations for risk management to taking an action for reduce risk and discovering a new opportunity owing to the exchange rate be able to explain part of the within-country cross sectional variation (Maria, 2000). Stephen et al. (2005) defined "exchange rate is the price of one country's currency for another's" and "exchange rate risk is the natural consequence of international operations in a world where foreign currency values move up and down" which a nominal exchange rate risk is an independent source of risk (Gerard and Mathijs, 2010).

Many previous studied have claimed that the exchange rate has a significant effect on financial sector and also an economy. Faff and Howard (1999) mentioned that "exchanger risk had important impact on the risks faced by bank and financial companies". Sohnke and Andrew (2006) noted that "the foreign exchange rate risk is in part a source of non-diversifiable risk" and also has a significant effect on the consumption (Evzen and Tigran, 2009).

Additionally, exchange rate is an important determinant of sovereign risks which in case if a country has foreign currency debt and has a significant impact on depreciation therefore the depreciation able to be an affect of 
sovereign risk (Michael et al, 2009).

For this study, we can identify the exchange rate risk on Interbank interest rate in case of Thailand by explore the relationship between an exchange rate of AEC member countries and BIBOR and degree of pass through in every tenor of BIBOR.

\section{Experimental Methodology and Hypothesis}

Owing to an exchange rate is a systematic risk so in this study we will use an exchange rate to extend our knowledge and understanding of an exchange rate risk dynamics on BIBOR, such as how many degree of pass through, and direction of the relationship between AEC's exchange rates and BIBOR.

In practice, almost all trading of currencies takes place in terms of the U.S. dollar because of it able to be reduces the number of possible cross-currency quotes and makes triangular arbitrage more difficult. In case, if all currencies trade against each other it would make inconsistencies more likely. However, this research aims to study the relationship between the currency of AEC member countries and BIBOR in case of Thailand interbank market thereby in this case we will apply the currency of AEC member countries against Thai Baht. Consequently, we use an exchange rate of 9 currencies of AEC member countries against Thai baht consists of Brunei Dollar (BND), Cambodian Riel (KHR), Indonesian Rupiah (IDR), Lao Kip (LAK), Malaysia Ringgit (MYR), Myanmar Kyats (MMK), Philippine Peso (PHP), Singapore Dollar (SGD), and Vietnamese Dong (VND).

In this study the source of data such the BIBOR and exchange rate are from the BOT which cover the period from January 2006 to December 2011 and we base the BIBOR on the average of borrowing rate quoted by predetermined banks, the exchange rate is base on the BOT's mid rate. In the first part of result we will describe the basic statistic of 9 currencies of AEC member countries. Next, we continually to investigate the relationship and a degree of pass through between exchange rates and BIBOR with econometric test. However, before we begin to analyze with econometric test we have to test the unit root owing to our data is a time series data that it can be non-stationary. Then we will explain the dynamic time path in each variable with variance decomposition test, impulse response function test, and Granger causality test, respectively.

\section{Empirical Results}

\subsection{Description the Basic Statistics of 9 Currencies of AEC Member Countries}

Before analyze with econometric test, this section we describe the basic statistics of 9 currencies of AEC member countries consists of BND, KHR, IDR, LAK, MYR, MMK, PHP, SGD, and VND. The sample period is running from January 2006 till December 2011.

Table 1 summarized basic statistics of 9 currencies of AEC member countries from 2006 to 2011. The standard deviation indicated that the KHR, IDR, LAK, and VND were less volatile than other currencies whereas the BND and SGD were the highest volatile. The IDR and VND had negative skewness that suggested the distribution is skewed left but close to normal distribution. For the BND, KHR, LAK, MYR, MMK, PHP, and SGD those rates are skewed right and also close to normal distribution except LAK. The kurtosis value suggested the LAK is more peaked than other currencies.

As shown in figure 2, we found the trend of KHR, IDR, MYR, MMK, and VND were dropped down trend throughout the sample period. The BND and SGD were fluctuated during the sample period especially during 2008 to 2009 owing to at that time was happened the financial crisis around the world. Conversely, in the middle of year 2008 the PHP was increased while at that time the other currency was dropped. However, the LAK was only one currency that not too much changed and it was little dropped in year 2008.

Table 1. Basic statistic of AEC's exchange rate

\begin{tabular}{llllllllll}
\hline & BND & KHR & IDR & LAK & MYR & MMK & PHP & SGD & VND \\
\hline Mean & 23.5352 & 0.0087 & 0.0037 & 0.0039 & 10.0926 & 5.4984 & 0.7313 & 23.5437 & 0.0021 \\
Median & 23.4570 & 0.0086 & 0.0037 & 0.0039 & 10.0525 & 5.3826 & 0.7321 & 23.4586 & 0.0021 \\
Maximum & 24.7405 & 0.0102 & 0.0043 & 0.0049 & 11.0104 & 6.4964 & 0.8108 & 24.7542 & 0.0026 \\
Minimum & 22.2030 & 0.0071 & 0.0030 & 0.0035 & 9.5805 & 4.6443 & 0.6864 & 22.2071 & 0.0015 \\
Std. Dev. & 0.5468 & 0.0008 & 0.0004 & 0.0003 & 0.3604 & 0.4815 & 0.0264 & 0.5446 & 0.0003 \\
Skewness & 0.0721 & 0.2578 & -0.0643 & 1.7848 & 0.8462 & 0.4341 & 0.7794 & 0.0730 & -0.0795 \\
Kurtosis & 2.7992 & 2.1627 & 1.9275 & 7.3163 & 3.0175 & 2.2831 & 4.0503 & 2.8649 & 2.1885 \\
\hline
\end{tabular}



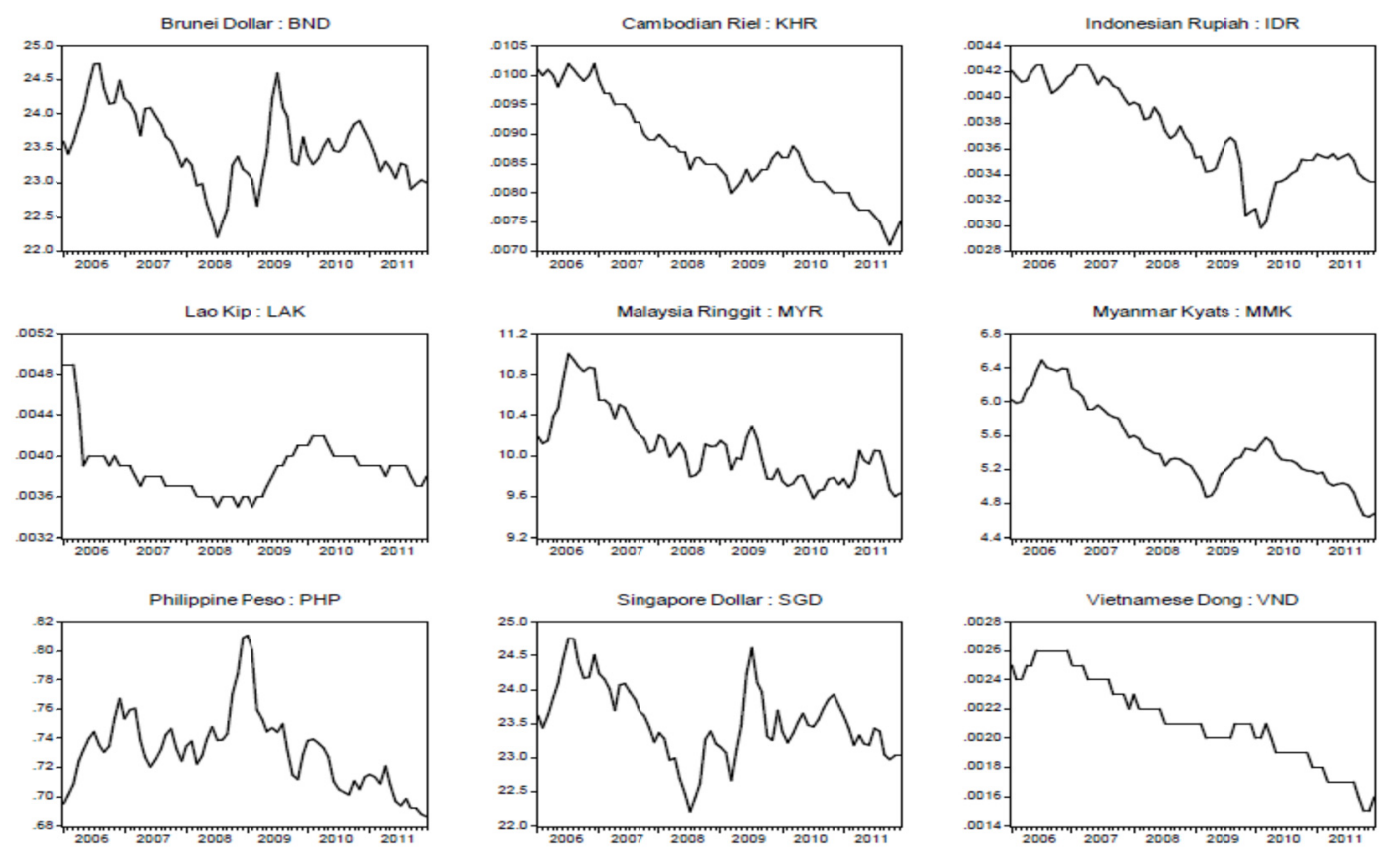

Figure 2. 9 currencies of AEC member countries

Description: These figures depict the AEC's exchange rates against Thai Baht during the period from January 2006 to December 2011.

\subsection{Econometric Test}

After we have described the basic statistics of 9 currencies of AEC member countries, in this part we continue to analyze the relationship among exchange rate of AEC member countries and BIBOR by using the linear regression model that useful for description of the dynamic behavior of economic and financial time series.

Following the specification of the econometric model, we apply the multiple linear regression model into our study as follows:

$$
\text { BIBOR }_{\tau}=\alpha_{0}+\alpha_{1} \text { Exchange rate }_{t}+\varepsilon_{t}
$$

where $\alpha_{0}$ and $\alpha_{1}$ are a parameters, $\mathrm{BIBOR}_{\mathrm{t}}$ is the Bangkok Interbank Offered Rate, Exchange rate ${ }_{\mathrm{t}}$ is 9 currencies of AEC member countries which consist of BND, KHR, IDR, LAK, MYR, MMK, PHP, SGD, and VND, and $\varepsilon_{t}$ is an Error term.

\subsubsection{Unit Root Test}

Table 2. Unit root test (ADF-Trend and intercept)

\begin{tabular}{|c|c|c|c|c|c|}
\hline Variable & Level & $\mathrm{Lag}^{1}$ & Equation test & t-statistic & MacKinnon Critical \\
\hline BIBOR 1 week & $1^{\text {st }}$ difference & 0 & With trend and intercept & -3.40968 & $-3.16505^{* * *}$ \\
\hline BIBOR 1 month & & & & -3.41096 & $-3.16505^{* * *}$ \\
\hline BIBOR 2 months & & & & -3.50547 & $-3.47531 * *$ \\
\hline BIBOR 3 months & & & & -3.49480 & $-3.47531 * *$ \\
\hline BIBOR 6 months & & & & -3.43216 & $-3.16505^{* * *}$ \\
\hline BIBOR 9 months & & & & -3.44452 & $-3.16505^{* * *}$ \\
\hline BIBOR 12 months & & & & -3.49548 & $-3.47531 * *$ \\
\hline Brunei Dollar: BND & & & & -6.49677 & $-4.09455^{*}$ \\
\hline Cambodian Riel: KHR & & & & -7.68493 & $-4.09455^{*}$ \\
\hline Indonesian Rupiah: IDR & & & & -6.08542 & $-4.09455^{*}$ \\
\hline Lao Kip: LAK & & & & -7.07926 & $-4.09455^{*}$ \\
\hline Malaysia Ringgit: MYR & & & & -6.85796 & $-4.09455^{*}$ \\
\hline Myanmar Kyats: MMK & & & & -5.59311 & $-4.09455^{*}$ \\
\hline Philippine Peso: PHP & & & & -6.08350 & $-4.09455^{*}$ \\
\hline Singapore Dollar: SGD & & & & -6.47496 & $-4.09455^{*}$ \\
\hline Vietnamese Dong: VND & & & & -9.20168 & $-4.09455^{*}$ \\
\hline
\end{tabular}

Notes: $\mathrm{Lag}^{1}=$ Length (Automatic based on SIC) $* *=$ Significant at $0.01 ; * *=$ Significant at $0.05 ; * * *=$ Significant at 0.10. 
Owing to the econometric tests, we used the time series data to explore the degree of exchange rate risk on BIBOR thereby the data ought to be stationary data if not the result from econometric tests will be spurious regression. The tool to test a stationary data we used the unit root test with Augmented Dickey-Fuller (ADF).

As mentioned above, an exchange rate and BIBOR in our study may able to be non-stationary that will make a spurious relationship and the results will be unbelief therefore we must test a stationary in each variable with $\mathrm{ADF}$ and assumed the assumption for testing which following an equation as below:

$$
\begin{gathered}
\Delta Y_{t}=y Y_{t-1}+\sum_{i=1}^{\rho} \emptyset \Delta Y_{t-1}+\varepsilon_{t} \text { (random walk process } \\
\Delta Y_{t}=\alpha+y Y_{t-1}+\sum_{i=1}^{\rho} \emptyset \Delta Y_{t-1}+\varepsilon_{t} \text { (random walk with drift) } \\
\Delta Y_{t}=\alpha+\beta_{t}+y Y_{t-1}+\sum_{i=1}^{\rho} \emptyset \Delta Y_{t-1}+\varepsilon_{t} \text { (random walk with drift and linear time trend) }
\end{gathered}
$$

Then the null hypothesis of the ADF test is $\mathrm{H}_{0}: \rho=1$ and if $|\rho|<1$ that means $\mathrm{y}$ is stationary by the way if $\rho=1$ that means $y$ is non-stationary.

Table 2 presents result of a unit root test with ADF. We found the BIBOR in every tenor that consists of BIBOR 1 week, BIBOR 1month, BIBOR 2months, BIBOR 3months, BIBOR 6months, BIBOR 9months, and BIBOR 12 momths and 9 currencies of AEC member countries that consists of BND, KHR, IDR, LAK, MYR, MMK, PHP, SGD, and VND those are reject the null hypothesis at the $1^{\text {st }}$ difference with the significant level at $1 \%, 5 \%$ and $10 \%$ owing to the MacKinnon critical value is more than t-statistic that suggest they are stationary.

\begin{tabular}{|c|c|c|c|c|c|c|c|c|c|c|c|}
\hline Period & S.E. & BIBOR 1w & BND & KHR & IDR & LAK & MYR & MMK & PHP & SGD & VND \\
\hline 1 & 0.125 & 100.000 & 0.000 & 0.000 & 0.000 & 0.000 & 0.000 & 0.000 & 0.000 & 0.000 & 0.000 \\
\hline 2 & 0.213 & 95.186 & 0.000 & 0.108 & 0.626 & 0.327 & 1.130 & 2.066 & 0.264 & 0.136 & 0.158 \\
\hline 3 & 0.296 & 85.400 & 1.383 & 0.057 & 2.581 & 0.506 & 4.180 & 3.110 & 1.997 & 0.153 & 0.633 \\
\hline 4 & 0.378 & 72.643 & 4.002 & 0.166 & 5.499 & 0.680 & 7.118 & 2.791 & 4.897 & 0.503 & 1.700 \\
\hline 5 & 0.466 & 59.236 & 6.099 & 0.358 & 8.900 & 0.948 & 8.999 & 2.156 & 8.006 & 1.769 & 3.529 \\
\hline 6 & 0.555 & 48.030 & 6.965 & 0.465 & 12.269 & 1.180 & 9.655 & 1.625 & 10.771 & 3.618 & 5.421 \\
\hline 7 & 0.638 & 39.966 & 6.831 & 0.502 & 15.070 & 1.310 & 9.468 & 1.276 & 13.054 & 5.444 & 7.078 \\
\hline 8 & 0.710 & 34.496 & 6.187 & 0.512 & 17.032 & 1.379 & 8.889 & 1.075 & 14.880 & 7.038 & 8.512 \\
\hline 9 & 0.771 & 30.847 & 5.447 & 0.522 & 18.136 & 1.428 & 8.214 & 0.994 & 16.337 & 8.376 & 9.699 \\
\hline 10 & 0.821 & 28.422 & 4.830 & 0.553 & 18.503 & 1.478 & 7.595 & 1.017 & 17.526 & 9.475 & 10.604 \\
\hline Period & S.E. & BIBOR 1m & BND & KHR & IDR & LAK & MYR & MMK & PHP & SGD & VND \\
\hline 1 & 0.124 & 100.000 & 0.000 & 0.000 & 0.000 & 0.000 & 0.000 & 0.000 & 0.000 & 0.000 & 0.000 \\
\hline 2 & 0.214 & 94.602 & 0.012 & 0.017 & 0.477 & 0.789 & 0.346 & 3.419 & 0.312 & 0.016 & 0.010 \\
\hline 3 & 0.300 & 85.620 & 0.925 & 0.048 & 2.718 & 1.011 & 1.882 & 5.652 & 1.658 & 0.017 & 0.470 \\
\hline 4 & 0.384 & 74.001 & 2.751 & 0.322 & 6.185 & 1.262 & 3.955 & 5.740 & 3.868 & 0.325 & 1.590 \\
\hline 5 & 0.473 & 61.373 & 4.456 & 0.682 & 9.881 & 1.550 & 5.622 & 4.812 & 6.564 & 1.588 & 3.472 \\
\hline 6 & 0.564 & 50.476 & 5.318 & 0.923 & 13.178 & 1.725 & 6.327 & 3.797 & 9.373 & 3.543 & 5.341 \\
\hline 7 & 0.649 & 42.366 & 5.375 & 1.040 & 15.686 & 1.783 & 6.274 & 3.056 & 11.975 & 5.577 & 6.868 \\
\hline 8 & 0.722 & 36.722 & 4.973 & 1.090 & 17.340 & 1.798 & 5.874 & 2.604 & 14.175 & 7.364 & 8.062 \\
\hline 9 & 0.782 & 32.908 & 4.437 & 1.123 & 18.224 & 1.820 & 5.405 & 2.382 & 15.925 & 8.801 & 8.975 \\
\hline 10 & 0.830 & 30.360 & 3.964 & 1.176 & 18.469 & 1.874 & 4.988 & 2.342 & 17.285 & 9.897 & 9.646 \\
\hline Period & S.E. & BIBOR $2 \mathrm{~m}$ & BND & KHR & IDR & LAK & MYR & MMK & PHP & SGD & VND \\
\hline 1 & 0.128 & 100.000 & 0.000 & 0.000 & 0.000 & 0.000 & 0.000 & 0.000 & 0.000 & 0.000 & 0.000 \\
\hline 2 & 0.219 & 94.828 & 0.001 & 0.015 & 0.687 & 0.527 & 0.484 & 3.143 & 0.303 & 0.009 & 0.002 \\
\hline 3 & 0.304 & 85.459 & 1.157 & 0.046 & 2.973 & 0.807 & 2.235 & 5.313 & 1.591 & 0.059 & 0.359 \\
\hline
\end{tabular}

\subsubsection{Variance Decomposition Analysis}

Table 3. Variance decomposition test 


\begin{tabular}{|c|c|c|c|c|c|c|c|c|c|c|c|}
\hline 4 & 0.389 & 73.651 & 3.311 & 0.307 & 6.400 & 1.094 & 4.266 & 5.309 & 3.677 & 0.596 & 1.390 \\
\hline 5 & 0.477 & 61.169 & 5.129 & 0.631 & 10.025 & 1.412 & 5.687 & 4.397 & 6.228 & 2.130 & 3.191 \\
\hline 6 & 0.565 & 50.469 & 5.953 & 0.835 & 13.241 & 1.629 & 6.165 & 3.478 & 8.955 & 4.222 & 5.053 \\
\hline 7 & 0.646 & 42.453 & 5.939 & 0.922 & 15.686 & 1.730 & 5.999 & 2.836 & 11.555 & 6.264 & 6.616 \\
\hline 8 & 0.716 & 36.809 & 5.479 & 0.952 & 17.296 & 1.780 & 5.582 & 2.466 & 13.790 & 7.984 & 7.862 \\
\hline 9 & 0.774 & 32.944 & 4.901 & 0.973 & 18.151 & 1.832 & 5.147 & 2.317 & 15.579 & 9.319 & 8.837 \\
\hline 10 & 0.820 & 30.323 & 4.392 & 1.016 & 18.376 & 1.911 & 4.776 & 2.348 & 16.973 & 10.308 & 9.576 \\
\hline Period & S.E. & BIBOR $3 \mathrm{~m}$ & BND & KHR & IDR & LAK & MYR & MMK & PHP & SGD & VND \\
\hline 1 & 0.130 & 100.000 & 0.000 & 0.000 & 0.000 & 0.000 & 0.000 & 0.000 & 0.000 & 0.000 & 0.000 \\
\hline 2 & 0.221 & 95.127 & 0.011 & 0.016 & 1.056 & 0.449 & 0.628 & 2.372 & 0.323 & 0.000 & 0.019 \\
\hline 3 & 0.308 & 85.543 & 1.317 & 0.040 & 3.668 & 0.817 & 2.366 & 4.073 & 1.727 & 0.055 & 0.395 \\
\hline 4 & 0.395 & 73.478 & 3.603 & 0.253 & 7.260 & 1.152 & 4.118 & 4.037 & 3.960 & 0.726 & 1.411 \\
\hline 5 & 0.484 & 60.910 & 5.467 & 0.495 & 10.982 & 1.479 & 5.225 & 3.311 & 6.573 & 2.462 & 3.096 \\
\hline 6 & 0.571 & 50.231 & 6.299 & 0.634 & 14.237 & 1.697 & 5.545 & 2.610 & 9.264 & 4.642 & 4.841 \\
\hline 7 & 0.651 & 42.271 & 6.281 & 0.687 & 16.687 & 1.807 & 5.359 & 2.140 & 11.778 & 6.646 & 6.344 \\
\hline 8 & 0.719 & 36.674 & 5.815 & 0.702 & 18.281 & 1.872 & 4.988 & 1.891 & 13.923 & 8.273 & 7.582 \\
\hline 9 & 0.775 & 32.835 & 5.229 & 0.716 & 19.111 & 1.938 & 4.613 & 1.830 & 15.640 & 9.514 & 8.574 \\
\hline 10 & 0.820 & 30.222 & 4.707 & 0.752 & 19.310 & 2.029 & 4.296 & 1.928 & 16.988 & 10.428 & 9.340 \\
\hline Period & S.E. & BIBOR $6 \mathrm{~m}$ & $\mathrm{BND}$ & KHR & IDR & LAK & MYR & MMK & PHP & SGD & VND \\
\hline 1 & 0.129 & 100.000 & 0.000 & 0.000 & 0.000 & 0.000 & 0.000 & 0.000 & 0.000 & 0.000 & 0.000 \\
\hline 2 & 0.223 & 94.853 & 0.093 & 0.067 & 1.249 & 0.385 & 1.088 & 1.837 & 0.351 & 0.000 & 0.076 \\
\hline 3 & 0.314 & 85.191 & 1.617 & 0.042 & 3.784 & 0.824 & 3.069 & 2.959 & 1.943 & 0.151 & 0.419 \\
\hline 4 & 0.405 & 73.349 & 3.912 & 0.208 & 7.098 & 1.170 & 4.547 & 2.724 & 4.447 & 1.167 & 1.378 \\
\hline 5 & 0.497 & 61.202 & 5.544 & 0.417 & 10.616 & 1.483 & 5.218 & 2.120 & 7.252 & 3.269 & 2.880 \\
\hline 6 & 0.584 & 50.881 & 6.159 & 0.544 & 13.799 & 1.702 & 5.257 & 1.630 & 9.999 & 5.607 & 4.422 \\
\hline 7 & 0.662 & 43.141 & 6.028 & 0.603 & 16.291 & 1.830 & 4.976 & 1.330 & 12.456 & 7.567 & 5.779 \\
\hline 8 & 0.728 & 37.658 & 5.535 & 0.631 & 17.977 & 1.918 & 4.614 & 1.193 & 14.481 & 9.055 & 6.939 \\
\hline 9 & 0.781 & 33.866 & 4.970 & 0.659 & 18.901 & 2.002 & 4.282 & 1.202 & 16.066 & 10.147 & 7.905 \\
\hline 10 & 0.823 & 31.263 & 4.489 & 0.707 & 19.176 & 2.100 & 4.009 & 1.342 & 17.302 & 10.943 & 8.670 \\
\hline Period & S.E. & BIBOR 9m & $\mathrm{BND}$ & KHR & IDR & LAK & MYR & MMK & PHP & SGD & VND \\
\hline 1 & 0.132 & 100.000 & 0.000 & 0.000 & 0.000 & 0.000 & 0.000 & 0.000 & 0.000 & 0.000 & 0.000 \\
\hline 2 & 0.232 & 94.084 & 0.199 & 0.001 & 1.556 & 0.490 & 1.467 & 1.656 & 0.492 & 0.000 & 0.054 \\
\hline 3 & 0.329 & 84.107 & 1.932 & 0.083 & 4.230 & 0.946 & 3.301 & 2.600 & 2.428 & 0.117 & 0.256 \\
\hline 4 & 0.424 & 72.732 & 4.166 & 0.349 & 7.534 & 1.247 & 4.298 & 2.361 & 5.182 & 1.154 & 0.977 \\
\hline 5 & 0.516 & 61.113 & 5.636 & 0.557 & 11.087 & 1.517 & 4.594 & 1.824 & 8.060 & 3.367 & 2.244 \\
\hline 6 & 0.603 & 51.137 & 6.132 & 0.637 & 14.371 & 1.709 & 4.463 & 1.398 & 10.758 & 5.763 & 3.631 \\
\hline 7 & 0.678 & 43.576 & 5.940 & 0.648 & 16.973 & 1.828 & 4.154 & 1.139 & 13.109 & 7.699 & 4.935 \\
\hline 8 & 0.741 & 38.173 & 5.436 & 0.638 & 18.739 & 1.918 & 3.832 & 1.019 & 15.006 & 9.125 & 6.114 \\
\hline 9 & 0.790 & 34.413 & 4.892 & 0.632 & 19.710 & 2.008 & 3.560 & 1.033 & 16.466 & 10.152 & 7.135 \\
\hline 10 & 0.830 & 31.817 & 4.447 & 0.648 & 20.010 & 2.106 & 3.348 & 1.174 & 17.596 & 10.890 & 7.964 \\
\hline Period & S.E. & BIBOR $12 \mathrm{~m}$ & BND & KHR & IDR & LAK & MYR & MMK & PHP & SGD & VND \\
\hline 1 & 0.138 & 100.000 & 0.000 & 0.000 & 0.000 & 0.000 & 0.000 & 0.000 & 0.000 & 0.000 & 0.000 \\
\hline 2 & 0.243 & 93.711 & 0.298 & 0.008 & 1.816 & 0.358 & 1.803 & 1.394 & 0.502 & 0.000 & 0.109 \\
\hline 3 & 0.344 & 83.470 & 2.172 & 0.172 & 4.533 & 0.774 & 3.763 & 2.107 & 2.557 & 0.155 & 0.298 \\
\hline 4 & 0.442 & 71.988 & 4.455 & 0.529 & 7.739 & 1.040 & 4.605 & 1.823 & 5.533 & 1.315 & 0.973 \\
\hline 5 & 0.535 & 60.356 & 5.871 & 0.764 & 11.220 & 1.288 & 4.699 & 1.363 & 8.607 & 3.701 & 2.131 \\
\hline 6 & 0.621 & 50.405 & 6.296 & 0.828 & 14.508 & 1.483 & 4.444 & 1.031 & 11.411 & 6.202 & 3.392 \\
\hline 7 & 0.694 & 42.915 & 6.053 & 0.813 & 17.166 & 1.621 & 4.092 & 0.835 & 13.783 & 8.129 & 4.594 \\
\hline 8 & 0.753 & 37.606 & 5.521 & 0.780 & 18.998 & 1.736 & 3.769 & 0.745 & 15.648 & 9.482 & 5.715 \\
\hline 9 & 0.800 & 33.929 & 4.975 & 0.755 & 20.017 & 1.847 & 3.512 & 0.769 & 17.053 & 10.426 & 6.717 \\
\hline 10 & 0.836 & 31.387 & 4.547 & 0.754 & 20.343 & 1.958 & 3.316 & 0.914 & 18.131 & 11.100 & 7.548 \\
\hline
\end{tabular}

In order to investigate the relationship among the exchange rate and BIBOR, we used variance decomposition analysis to explain interrelationships by comparing "its own innovation" and "innovation in the other variables". Therefore, the result in this subsection will show us which exchange rate has more significant relation on 
BIBOR.

From table 3, we will see clearly which both of the IDR and PHP have more significant relation on BIBOR than other currencies in every tenor of BIBOR on the other hand the KHR and the LAK have less relationship on BIBOR. In addition, we also found the IDR and PHP both have more significant relation on BIBOR in tenor 12 months than 1 week that means both of the IDR and PHP vary directly with the tenor of BIBOR.

\subsubsection{Impulse Response Function Analysis}

Response to Cholesky One S.D. Innovations \pm 2 S.E.
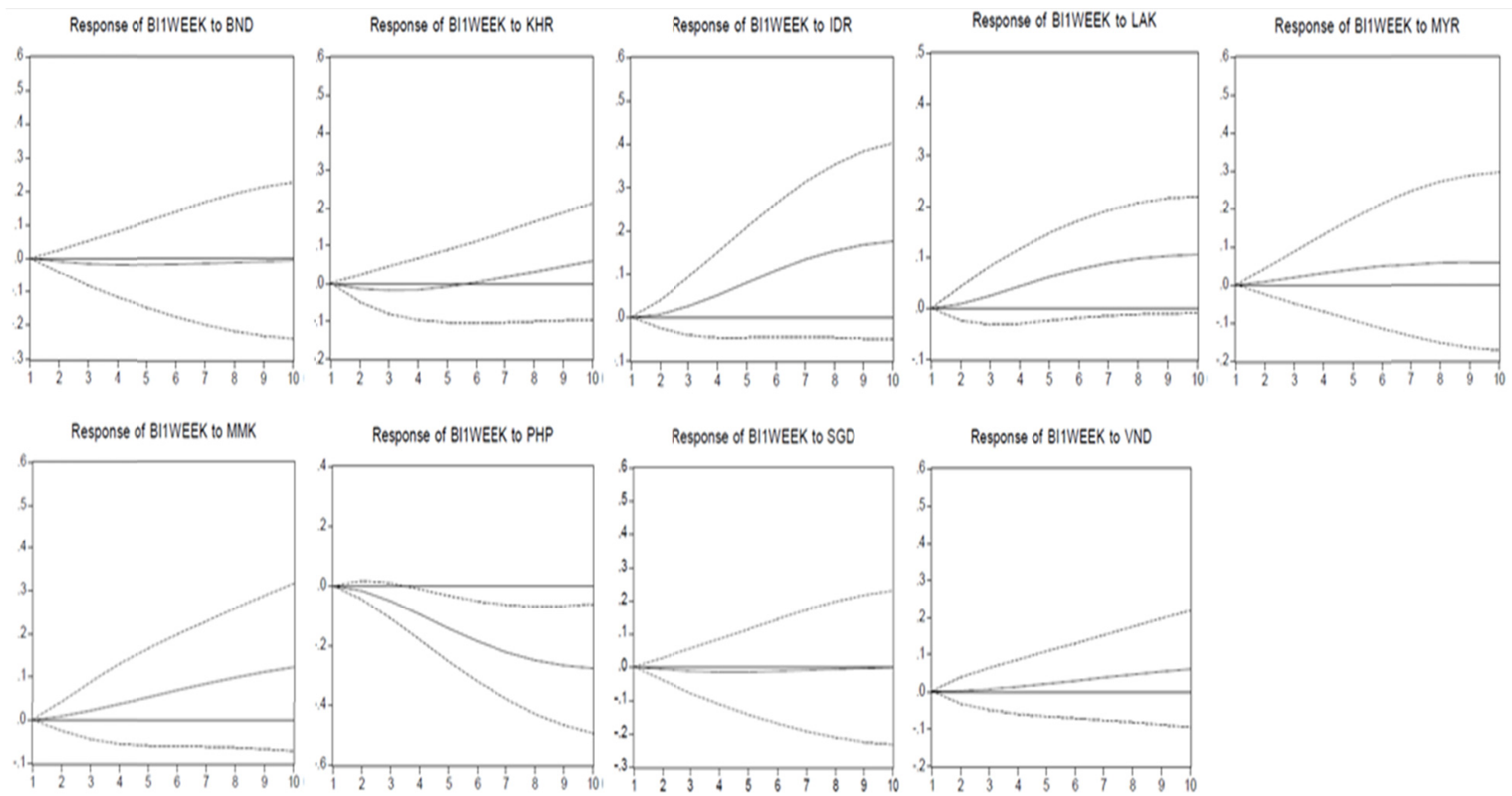

Figure 3. Impulse responses of BIBOR 1 week to BND, KHR, IDR, LAK, MYR, MMK, PHP, SGD, and VND
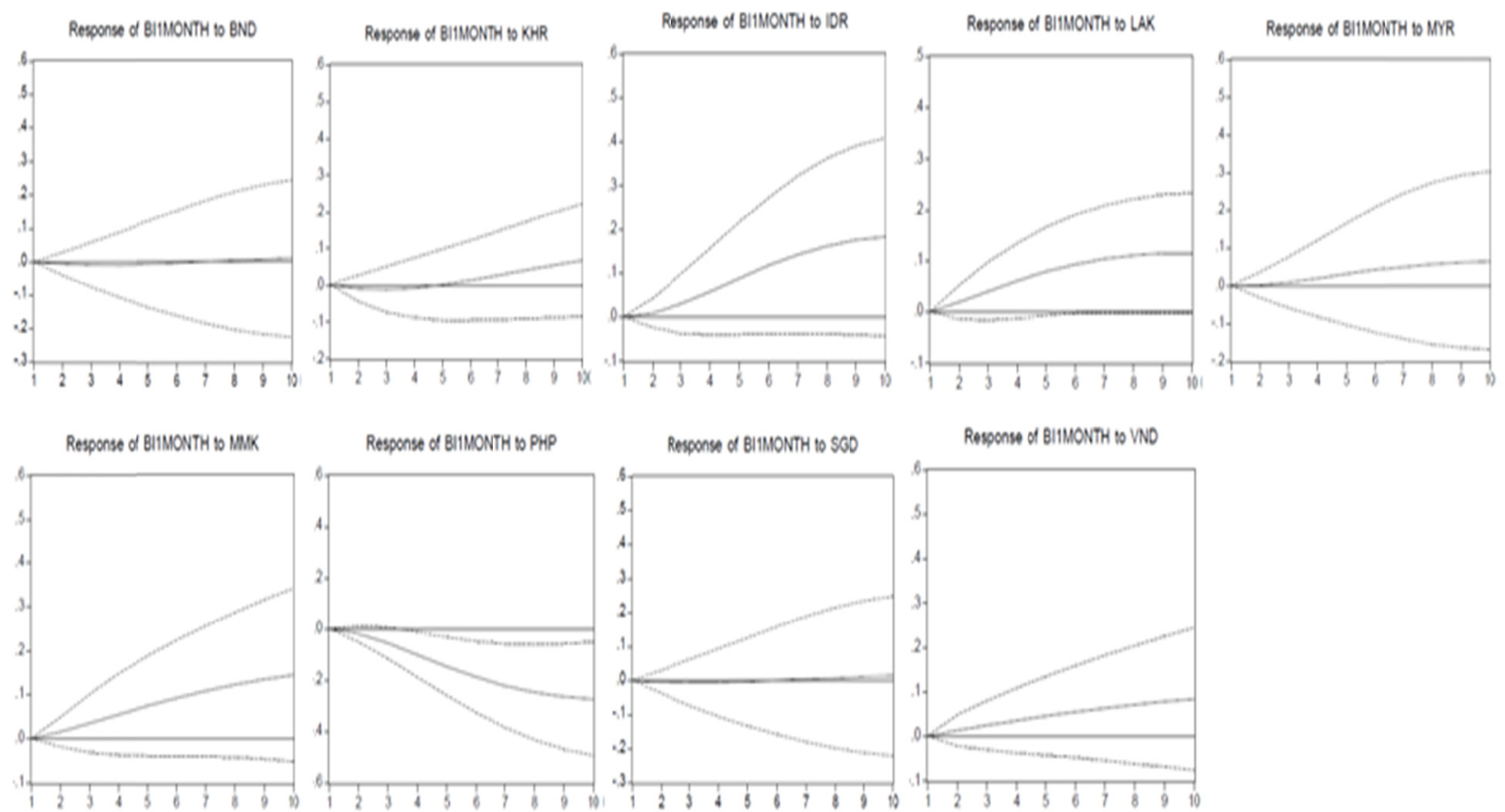

Figure 4. Impulse responses of BIBOR 1 month to BND, KHR, IDR, LAK, MYR, MMK, PHP, SGD, and VND 

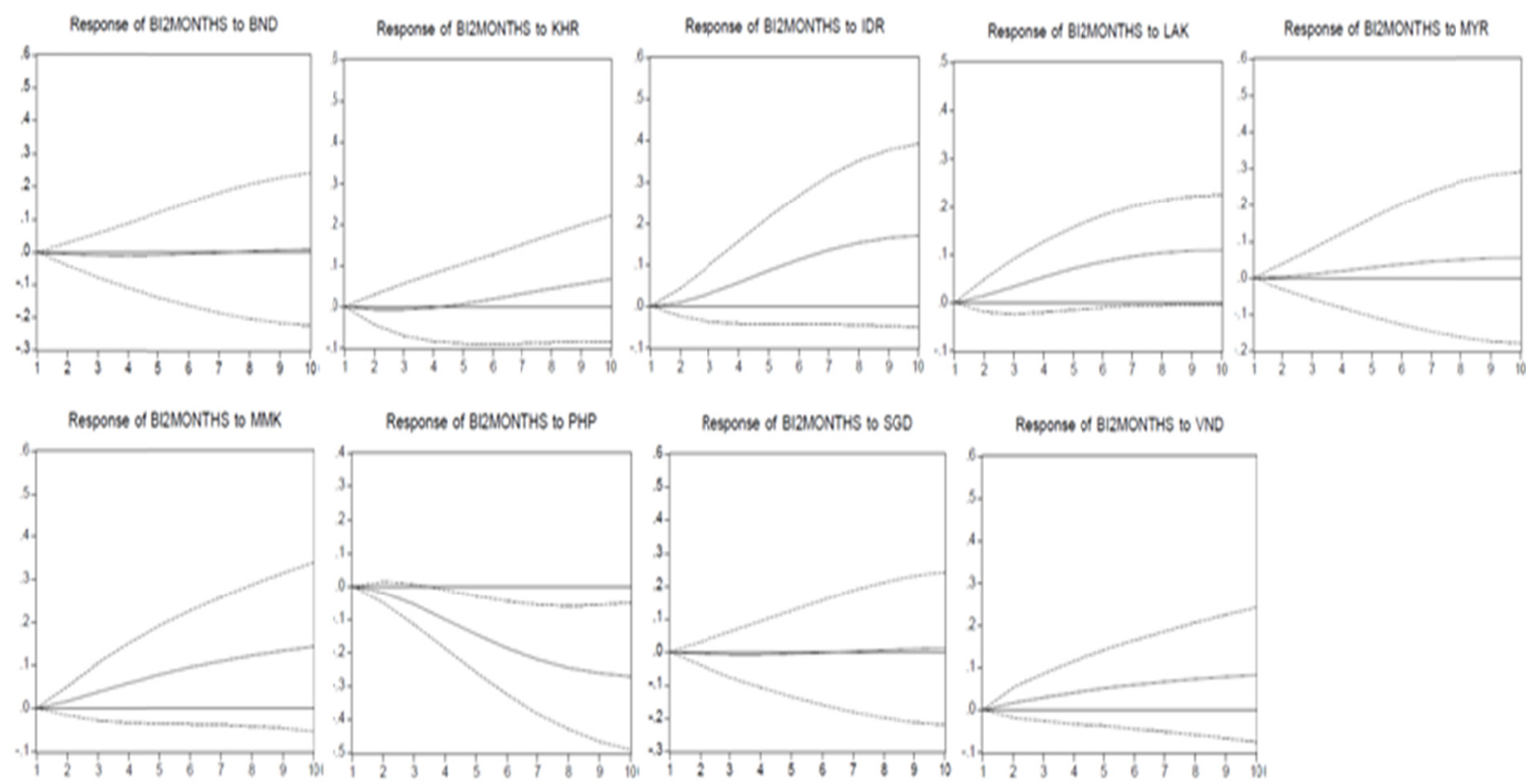

Figure 5. Impulse responses of BIBOR 2 months to BND, KHR, IDR, LAK, MYR, MMK, PHP, SGD, and VND
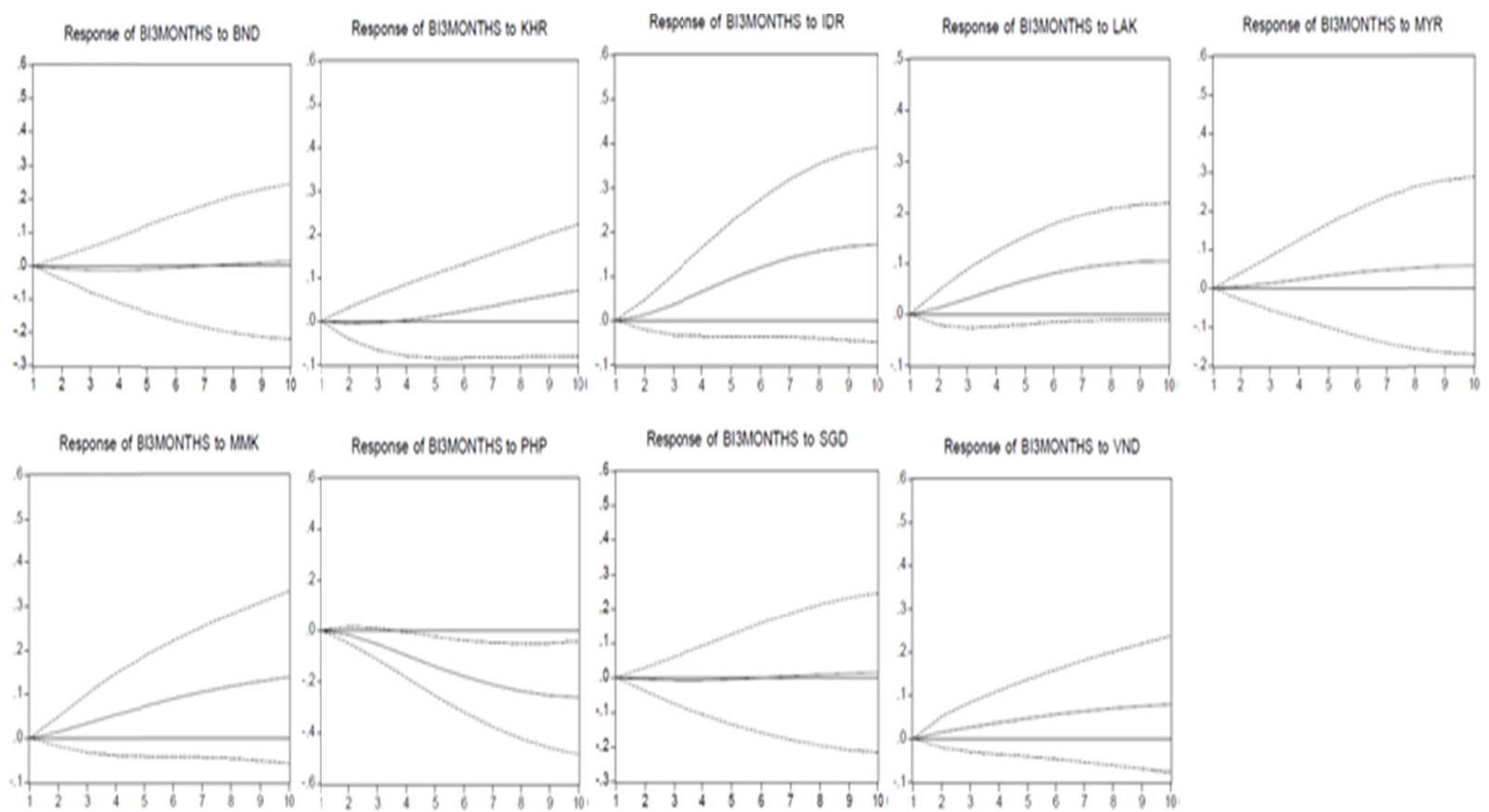

Figure 6. Impulse responses of BIBOR 3 months to BND, KHR, IDR, LAK, MYR, MMK, PHP, SGD, and VND 

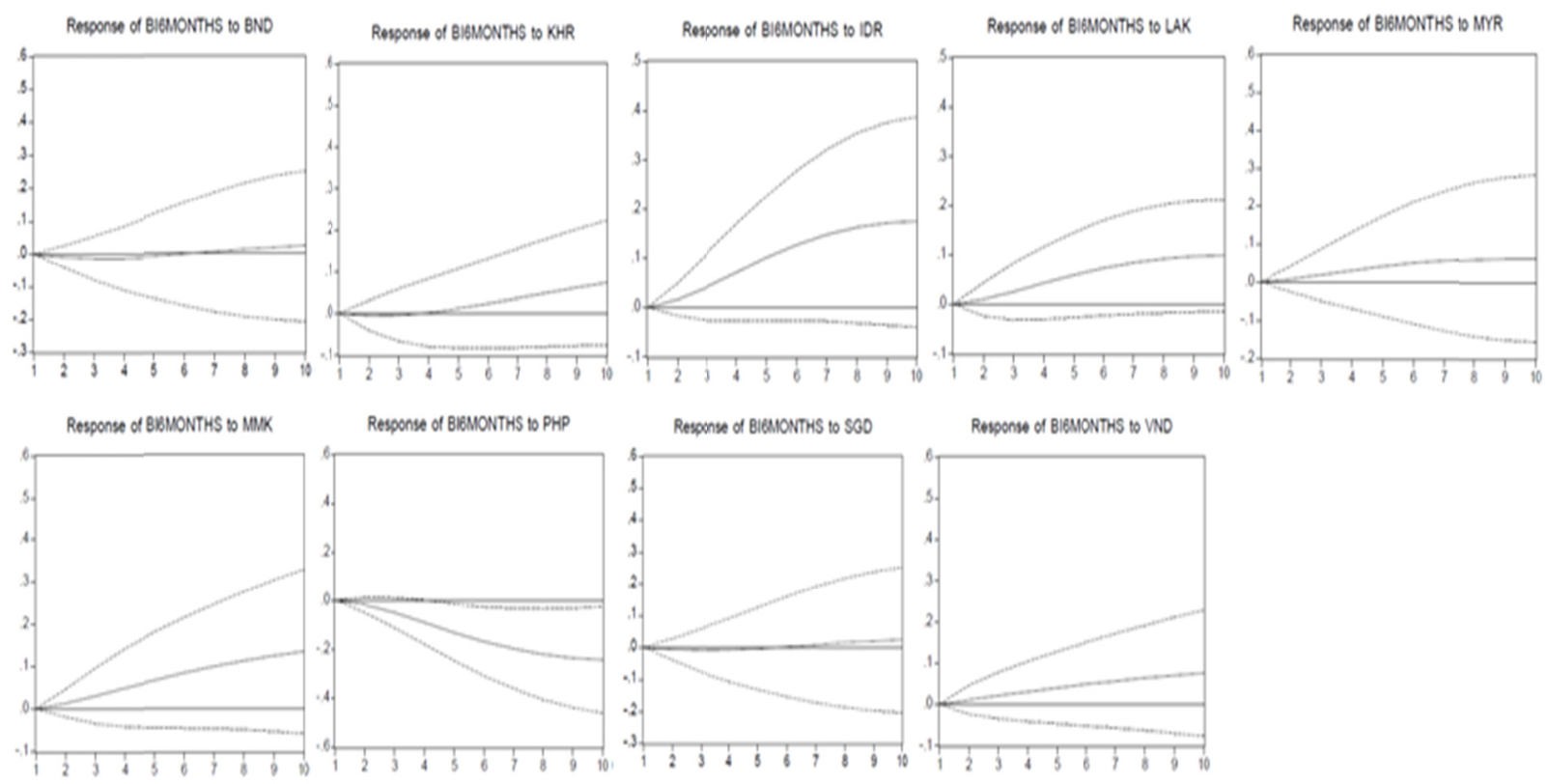

Figure 7. Impulse responses of BIBOR 6 months to BND, KHR, IDR, LAK, MYR, MMK, PHP, SGD, and VND
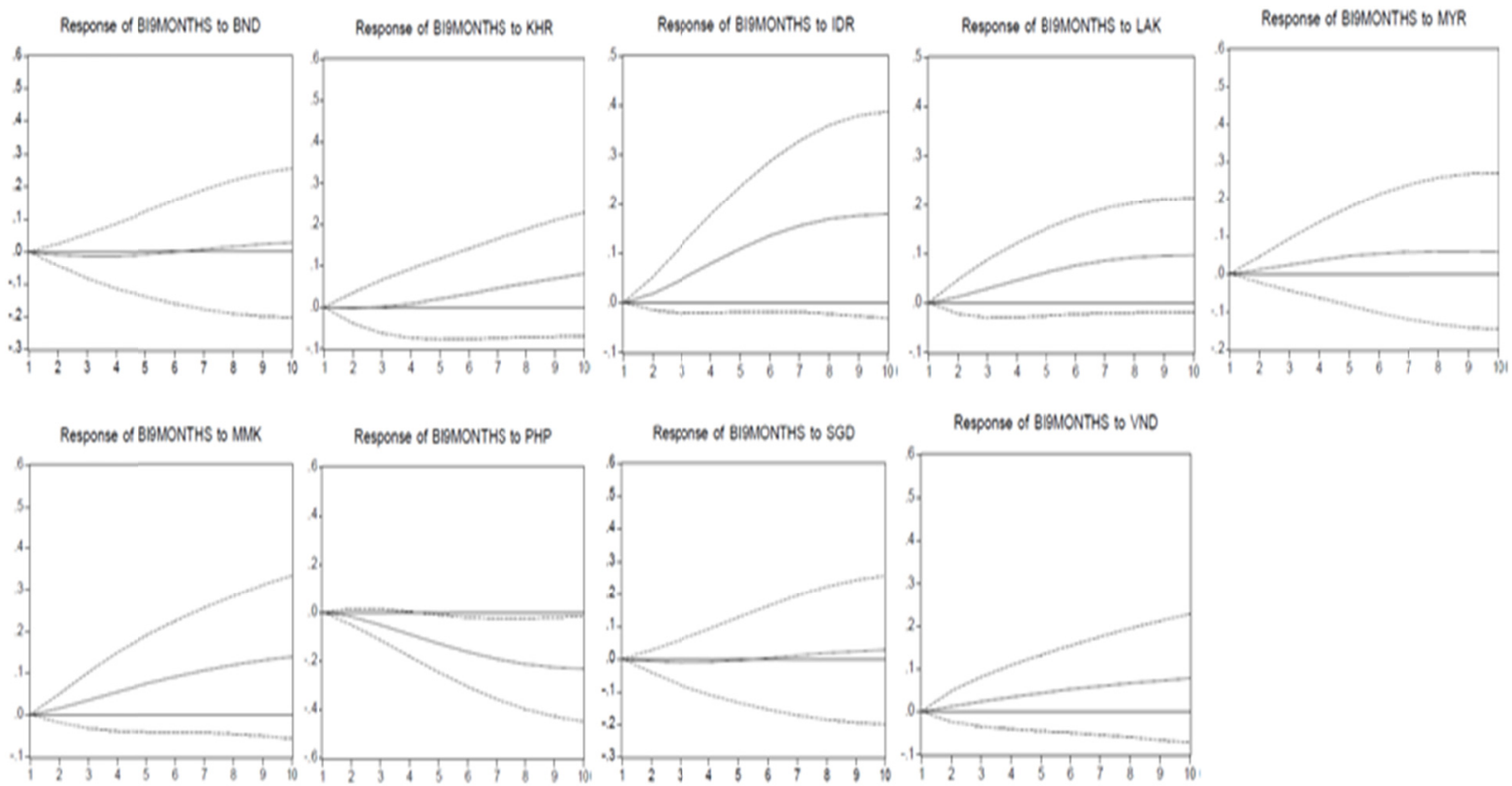

Figure 8. Impulse responses of BIBOR 9 months to BND, KHR, IDR, LAK, MYR, MMK, PHP, SGD, and VND 

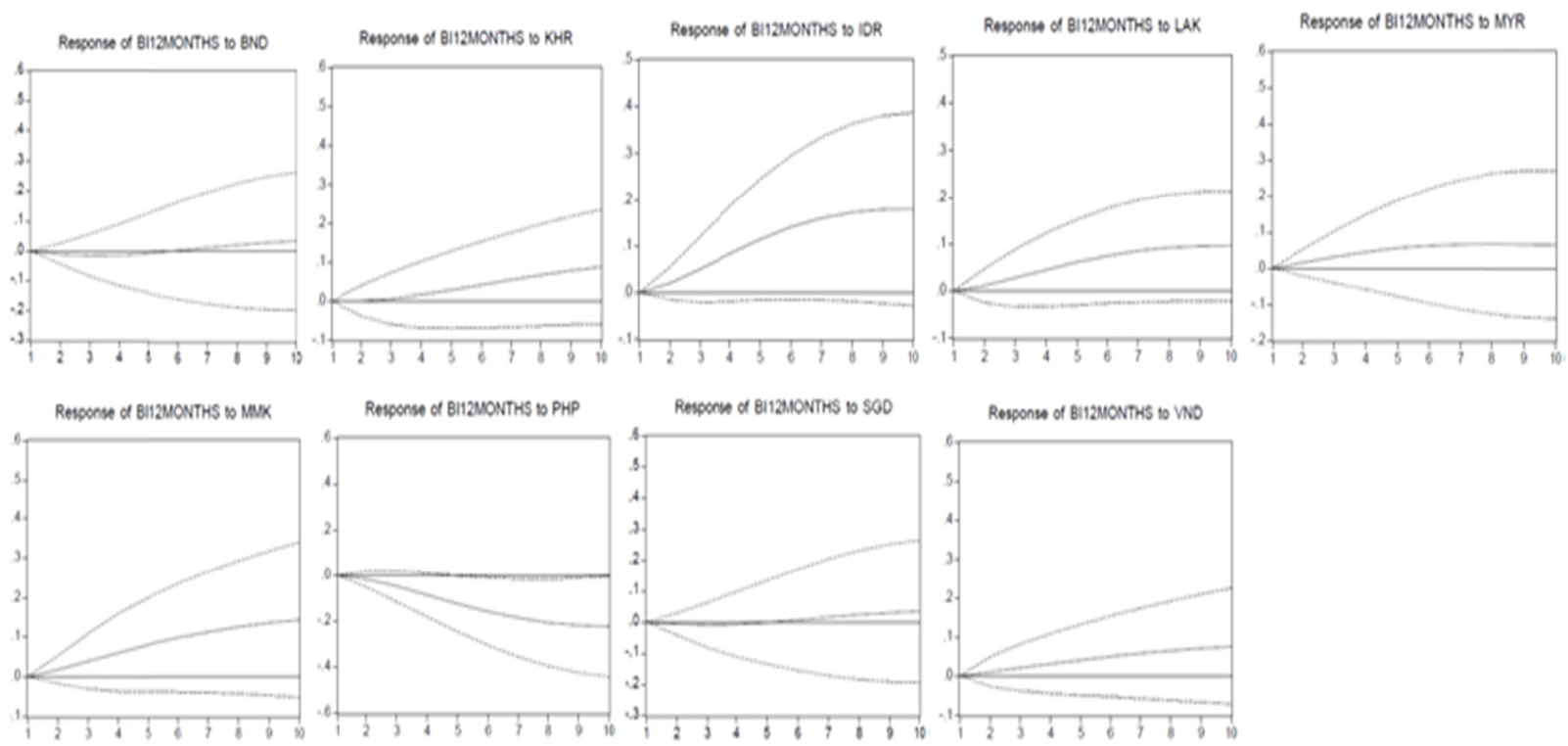

Figure 9. Impulse responses of BIBOR 12 months to BND, KHR, IDR, LAK, MYR, MMK, PHP, SGD, and VND

Owing to the previous subsection, it is not clearly to explain the relationship between variables also in our study we used only some variables that may affect to BIBOR therefore we will study the other tools to helping us analyze and make clearly relationship between the variables. As a result, we will use the impulse response function test that will explain in the next part.

The impulse response function is present us the dynamic time path of variable that can explain both present and future effects of variable which we interested when the other variable has changes immediately or shock. Therefore, this subsection analyze the response of BIBOR when 9 currencies of AEC member countries have change that the result can tell us the direction of relationship both short-run and long-run relations.

The impulse response function's graphs present an impact of exchange rate shocks on BIBOR, as a result of this test has found as follows:

1) Brunei Dollar (BND): an impact of BND shock on BIBOR, it was little dropped at the beginning and throughout a long-run relationship.

2) Cambodian Riel (KHR): an impact of KHR shock on BIBOR, it was little dropped down at the beginning afterward it was increased in long-run relationship.

3) Indonesian Rupiah (IDR): an impact of IDR shock on BIBOR, it was increased from the beginning and continues to increase in long-run.

4) Lao Kip (LAK): an impact of LAK shock on BIBOR, it seemed like the IDR but the degree of change was less than IDR and was slow down in long-run.

5) Malaysia Ringgit (MYR): an impact of MYR shock on BIBOR, it also seemed like IDR and LAK but the degree of change was less than both exchange rates.

6) Myanmar Kyats (MMK): an impact of MMK shock on BIBOR, it was almost seems like in case of LAK.

7) Philippine Peso (PHP): an impact of PHP shock on BIBOR, it was an only one currency that decreased from the beginning also continues to decrease in long-run.

8) Singapore Dollar (SGD): an impact of SGD shock on BIBOR, it was almost the same like BND's case.

9) Viet Nam (VND): an impact of VND shock on BIBOT, it was similar to the case of MYR.

To sum up, when the exchange rate shock happened the BND, KHR, IDR, LAK, MYR, MMK, SGD and VND were positive relation on BIBOR but the PHP was the only one currency which negative relation on BIBOR. Moreover, from all figures of impulse response function analysis we would find the BIBOR had the degree of positive relation with the IDR more than other currencies. 


\subsubsection{Granger Causality Test}

Table 4. Granger causality test

\begin{tabular}{|c|c|c|c|c|c|c|c|}
\hline \multirow{2}{*}{ Null Hypothesis: } & \multicolumn{7}{|c|}{$\mathrm{p}$ - values } \\
\hline & 1 week & 1 month & 2 months & 3 months & 6 months & 9 months & 12 months \\
\hline BND does not Granger Cause BIBOR & 0.8962 & 0.9309 & 0.9138 & 0.8859 & 0.8238 & 0.7865 & 0.7722 \\
\hline BIBOR does not Granger Cause BND & 0.6734 & 0.6139 & 0.5806 & 0.5986 & 0.6218 & 0.6171 & 0.6073 \\
\hline KHR does not Granger Cause BIBOR & 0.3605 & 0.3893 & 0.4676 & 0.4826 & 0.4408 & 0.4580 & 0.4450 \\
\hline BIBOR does not Granger Cause KHR & 0.9459 & 0.8912 & 0.8727 & 0.9040 & 0.8958 & 0.9251 & 0.9161 \\
\hline IDR does not Granger Cause BIBOR & 0.2883 & 0.2563 & 0.2930 & 0.2711 & 0.2296 & 0.1895 & 0.1727 \\
\hline BIBOR does not Granger Cause IDR & 0.2144 & 0.1983 & 0.2042 & 0.2054 & 0.2282 & 0.2458 & 0.2635 \\
\hline LAK does not Granger Cause BIBOR & 0.2007 & $0.1615^{*}$ & 0.1842 & 0.2151 & 0.2510 & 0.2752 & 0.2786 \\
\hline BIBOR does not Granger Cause LAK & $0.0948^{*}$ & $0.0963 *$ & $0.0923 *$ & $0.0906^{*}$ & $0.0904 *$ & $0.0913 *$ & $0.0916^{*}$ \\
\hline MYR does not Granger Cause BIBOR & 0.8246 & 0.8462 & 0.8933 & 0.8791 & 0.8206 & 0.7645 & 0.6797 \\
\hline BIBOR does not Granger Cause MYR & $0.0413^{*}$ & $0.0313^{*}$ & $0.0268 *$ & $0.0251 *$ & $0.0225^{*}$ & $0.0195 *$ & $0.0182 *$ \\
\hline MMK does not Granger Cause BIBOR & 0.4588 & 0.3306 & 0.3250 & 0.3603 & 0.3803 & 0.3526 & 0.3248 \\
\hline BIBOR does not Granger Cause MMK & 0.6582 & 0.5781 & 0.5226 & 0.5266 & 0.4776 & 0.5589 & 0.5552 \\
\hline PHP does not Granger Cause BIBOR & $0.0269 *$ & $0.0374 *$ & $0.0389 *$ & $0.0488^{*}$ & $0.0731 *$ & $0.0894 *$ & $0.1090^{*}$ \\
\hline BIBOR does not Granger Cause PHP & 0.2309 & 0.2073 & 0.1829 & 0.1773 & 0.1930 & 0.2020 & 0.2014 \\
\hline SGD does not Granger Cause BIBOR & 0.9212 & 0.9486 & 0.9425 & 0.9294 & 0.8855 & 0.8600 & 0.8475 \\
\hline BIBOR does not Granger Cause SGD & 0.6481 & 0.6034 & 0.5665 & 0.5802 & 0.6019 & 0.5991 & 0.5906 \\
\hline VND does not Granger Cause BIBOR & 0.7191 & 0.5541 & 0.5070 & 0.5473 & 0.6026 & 0.5702 & 0.5879 \\
\hline BIBOR does not Granger Cause VND & 0.7159 & 0.4942 & 0.4668 & 0.4930 & 0.5528 & 0.6265 & 0.6642 \\
\hline
\end{tabular}

Note: $*=$ reject null hypothesis at significant level $10 \%$.

Following the monetary policy, the interest rate and exchange rate are the some part of monetary policy therefore we suppose they should have causality to each other. From the previous subsections that presented the result of variance decomposition analysis, and impulse response function analysis that investigated about the relationship and degree of interrelationship between 9 currencies of AEC member countries and BIBOR which those results have shown us only the degree and direction of the relationship among variables. Therefore in the subsection we will be more clearly the understanding in causality of variables. The result from Granger causality test can explain which an exchange rate able to be cause the current and future of BIBOR. As a result, we will find which currency we should use the data of exchange rate in the past to indicate the BIBOR.

Regarding Granger (1969) and Sim (1972), the result of granger causality test can separate into three types consist of unidirectional causality, bidirectional causality or reverse causality, and independence. This subsection analyzes causality of the BIBOR and BND, the BIBOR and KHR, the BIBOR and IDR, the BIBOR and LAK, the BIBOR and MYR, the BIBOR and MMK, the BIBOR and PHP, the BIBOR and SGD, and the BIBOR and VND. And, the tenor of BIBOR is composed of BIBOR 1 week, BIBOR 1 month, BIBOR 2 months, BIBOR 3 months, BIBOR 6 months, BIBOR 9 months, and BIBOR 12 momths.

Table 4 reports granger causality test of our variables follow above during the sample period. The granger causality test found only PHP does a cause BIBOR in every tenor but the other currency does not a cause BIBOR.Conversely, we found every tenor of BIBOR does a cause LAK and MYR however when we compared by each tenor of LAK and MYR we found the BIBOR does a cause MYR more than LAK in every tenor.

\section{Concluding and Suggestion}

This research intends to apply VAR model to investigate the relationship between 9 currencies of AEC member countries. This study employs two groups of variables, including exchange rate and BIBOR. The exchange rates are composed of BND, KHR, IDR, LAK, MYR, MMK, PHP, SGD, and VND which in this study we specify all exchange rates against Thai Baht owing to we apply all variables in case of Thailand's interbank rate therefore its reasonable if we base on Thai Baht. The BIBOR consist of BIBOR 1 week, BIBOR 1 month, BIBOR 2 months, BIBOR 3 months, BIBOR 6 months, BIBOR 9 months, and BIBOR 12 months.

The result of econometric test, the variance decomposition analysis found the IDR and PHP have more relationship on BIBOR that suggest both of IDR and PHP can explain the interrelationship between exchange rate and BIBOR more than other currencies. Anyway, we also found the degree of relationship of the exchange rates vary directly with the tenor of BIBOR. In addition, in case the exchange rates shock happen almost every 
currency has positive relation on BIBOR especially the IDR. Even though, only the PHP has negative relation on BIBOR but the PHP is the only one currency that can explain the causality between exchange rate and BIBOR.

Following an evidence from the variance decomposition analysis and impulse response function analysis, this research concludes the exchange rate of AEC member countries such IDR and PHP have more significant impact on BIBOR in case of Thailand's money market than other currencies. For the future study, should be studied in the other variable such commercial banks loan and deposit rates that may have a significant impact on BIBOR.

\section{Acknowledgements}

We would like to thank you the service team of Bank of Thailand (BOT) for their supporting data and Wang Shanhui who provided any suggestions during the research.

\section{References}

Anoop, R., Rama, S., \& Sunil, K. (2007). The impact of discount rate changes on market interest rates: Evidence from three European countries and Japan. Journal of International Money and Finance, 26, 905-923. http://dx.doi.org/10.1016/j.jimonfin.2007.01.004

Asghar, A., \& Kevin, D. (2010). Macroeconomic determinants of credit risk: Recent evidence form a cross country study. International Review of Financial Analysis, 19, 165-171. http://dx.doi.org/10.1016/j.irfa.2010.03.001

Bangkok Interbank Offered Rate, Bank of Thailand. Retrieved from http://www.bot.or.th

Christian, U., \& Andreas, W. (2004). Estimating bilateral exposures in the German interbank market: Is there a danger of contagion? European Economic Review, 48, 827-849. http://dx.doi.org/10.1016/j.euroecorev.2003.12.009

Deborah, G., Gary, K., \& Simon, M. (2011). Understanding liquidity and credit risk in the financial crisis. Journal of Empirical Finance, 18, 903-914. http://dx.doi.org/10.1016/j.jempfin.2011.07.006

Dieter, N., \& Jan, S. (2011). Monetary policy implementation and overnight rate persistence. Journal of International Money and Finance, 30, 1375-1386. http://dx.doi.org/10.1016/j.jimonfin.2011.07.005

Evzen, K., \& Tigran, P. (2009). Macroeconomics sources of foreign exchange risk in new EU members. Journal of Banking \& Finance, 33, 2164-2173. http://dx.doi.org/10.1016/j.jbankfin.2009.05.015

Faff, R. W., \& Howard, P. F. (1999). Interest rate risk of Australian financial sector companies in a period of $\begin{array}{llll}\text { regulatory change. Pacific-Basin } & \text { Finance Journal, } & \text { 7(1), }\end{array}$ http://dx.doi.org/10.1016/S0927-538X(99)00002-5

Gerard, A., \& Mathijs, A. (2010). Inflation risk and international asset returns. Journal of Banking \& Finance, 34, 840-855. http://dx.doi.org/10.1016/j.jbankfin.2009.09.014

Hans, B., \& Oh, K. (2007). A simple continuous measure of credit risk. International Review of Financial Analysis, 16, 508-523. http://dx.doi.org/10.1016/j.irfa.2007.03.002

Ivan, P., \& Dele, L. (2007). Managerial Economics (3rd ed.). New York, NY: Blackwell Publishing Ltd.

Jens, T. (2006). Multiple equilibrium overnight rates in a dynamic interbank market game. Games and Economic Behavior, 56, 350-370. http://dx.doi.org/10.1016/j.geb.2005.08.006

Kiyotaka, N. (2006). The Bank of Japan's operating procedures and the identification of monetary policy shocks: A reexamination using the Bernanke-Mihov approach. Journal Japanese International Economies, 20, 406-433. http://dx.doi.org/10.1016/j.jjie.2005.01.001

Maria, V. (2000). Exchange rate and foreign inflation risk premiums in global equity returns. Journal of International Money and Finance, 19, 433-470. http://dx.doi.org/10.1016/S0261-5606(00)00008-5

Michael, D., Christopher, M., \& Marc, D. (2009). Identifying the effects of an exchange rate depreciation on country risk: Evidence from a natural experiment. Journal of International Money and Finance, 28, 1022-1044. http://dx.doi.org/10.1016/j.jimonfin.2008.10.004

Ming, H., Dimitri, M., \& Alireza, T. (2008). Monetary policy transparency and pass-through of retail interest rates. Journal of Banking \& Finance, 32, 501-511. http://dx.doi.org/10.1016/j.jbankfin.2007.06.012

Risk management framework. (2008). National Institution of Standard and Technology. Retrieved from http://csrc.nist.gov/groups/SMA/fisma/framework.html

Robert, A. (2011). Credit market equilibrium theory and evidence: Revisiting the structural versus reduced form 
credit risk model debate. Financial Research Letters, 8(1), 2-7. http://dx.doi.org/10.1016/j.frl.2010.08.002

Sohnke, M., \& Andrew, G. (2006). The impact of the introduction of the Euro on foreign exchange rate risk exposures. Journal of Empirical Finance, 13, 519-549. http://dx.doi.org/10.1016/j.jempfin.2006.01.002

Stephen, A., Randolph, W., \& Jeffrey, F. (2005). Corporate Finance (7th ed.). New York, NY: McGraw-Hill Companies Inc. 